Viso - Cadernos de estética aplicada Revista eletrônica de estética

ISSN 1981-4062

No 16, jan-jun/2015

http://www.revistaviso.com.br/

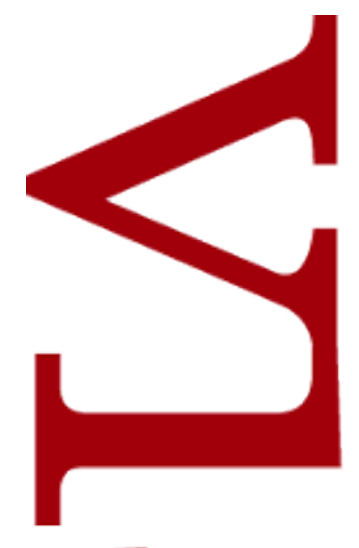

\title{
Dispositio: uma leitura retórica da forma musical contemporânea
} William Teixeira Silvio Ferraz 


\section{RESUMO}

\section{Dispositio: uma leitura retórica da forma musical contemporânea}

A forma é um dos parâmetros mais presentes nas análises do discurso e, do mesmo modo, o é na análise do discurso musical. Todavia, a complexificação estrutural da música contemporânea tem tornado cada vez mais improvável um pensamento analítico sobre essa dimensão que corresponda à realidade estética de seu material. Tendo em vista que a ideia de uma forma musical surge justamente do contato que a retórica e a música vêm tendo através dos tempos, a forma será discutida aqui a partir do referencial da Nova retórica, movimento importante para a retomada do pensamento retórico no século XX. Essa tão necessária readequação epistemológica faz emergirem outras questões de ordem pressuposicional, sendo discutidas brevemente aqui algumas delas, como a questão do tempo e das noções de matéria e forma. Por fim, a discussão terá sua aplicabilidade verificada através de análises formais da Sequenza XIV e de Les Mots Sont Allés..., ambas escritas pelo compositor Luciano Berio.

Palavras-chave: forma musical - música contemporânea - retórica musical - nova retórica

\section{ABSTRACT}

\section{Dispositio: A Rhetorical View of Contemporary Musical Form}

Form is a parameter very present in any model of analysis of discourse, and it is true for musical analysis as well. However, the increasing complexity of contemporary music is also hindering an analytical thinking on this dimension, in a way that matches to the aesthetic reality of musical material. Considering that the idea of a musical form comes from the contact which rhetoric and music have had through history, form will be discussed here from the framework of the New Rhetoric, an important movement for the resumption of rhetorical thought in the twentieth century. This much needed epistemological update does emerging other issues of pressuppositional order, and some of them will be discussed briefly such as the issue of time and the notions of matter and form. Finally, the discussion will have its applicability verified through formal analyses of Sequenza XIV and Les Mots Sont and Allés..., both musical pieces written by the composer Luciano Berio.

Keywords: musical form - contemporary music - musical rhetoric - new rhetoric 
TEIXEIRA, U; FERRAZ, S. "Dispositio: uma leitura retórica da forma musical contemporânea". In: Viso: Cadernos de estética aplicada, v. IX, n. 16 (jan-abr/2015), pp. 116-133.

DOI: $10.22409 / 1981-4062 / v 16 i / 199$

Aprovado: 12.07.2015. Publicado: 30.07.2015.

(C) 2015 William Teixeira; Silvio Ferraz. Esse documento é distribuído nos termos da licença Creative Commons Atribuição-NãoComercial 4.0 Internacional (CC-BY-NC), que permite, exceto para fins comerciais, copiar e redistribuir o material em qualquer formato ou meio, bem como remixá-lo, transformá-lo ou criar a partir dele, desde que seja dado o devido crédito e indicada a licença sob a qual ele foi originalmente publicado. Licença: http://creativecommons.org/licenses/by-nc/4.0/deed.pt_BR

Accepted: 12.07.2015. Published: 30.07.2015.

(C) 2015 William Teixeira; Silvio Ferraz. This document is distributed under the terms of a Creative Commons Attribution-NonCommercial 4.0 International license (CC-BY-NC) which allows, except for commercial purposes, to copy and redistribute the material in any medium or format and to remix, transform, and build upon the material, provided the original work is properly cited and states its license.

License: http://creativecommons.org/licenses/by-nc/4.0/ 


\section{Introdução}

Música e retórica tem tido um caminhar bastante próximo no decorrer da história. Desde as menções feitas a respeito da arte musical por Aristóteles, em seu tratado sobre a arte retórica, passando por Agostinho, o professor de retórica autor do De musica, a relação entre ambas viu seu auge a partir da Renascença, quando as academias italianas a estudaram em busca de uma arte de fato humana, como já vislumbrara Petrarca ao estudar Cícero. Quase que paralelamente, a efervescência humanista a que a Europa assistia fez com que também na Alemanha essa relação fosse aprofundada, sobretudo a partir dos reformadores protestantes que viram a potencialidade humana contida na música, a ponto de levar seu estudo, antes pertencente ao quadrivium, para as aulas de retórica, disciplina do mundano trivium. ${ }^{1}$

A retórica, a arte de persuadir em todas as situações, tem seu trabalho de concepção do discurso dividido basicamente em cinco partes: inventio, dispositio, elocutio, memoratio e pronunciatio. A inventio se ocupa da concepção das ideias e do modo como suas premissas serão geradas, através dos entimemas, que são seu próprio corpo constitutivo, sendo, em essência, um silogismo retórico. A dispositio trata da escolha dos dados e de sua adequação a determinado fim argumentativo. A elocutio abarca todas as técnicas de apresentação dos dados e a própria forma do discurso. Aqui também está contido o estudo a respeito das figuras retóricas. Por fim, tem-se a memoratio, que se refere à memorização do discurso e a pronunciatio, que trabalha toda questão expressiva do discurso, tudo o que se refere à emissão daquilo que fora trabalhado nas etapas anteriores, desde questões propriamente oratórias, até mesmo questões gestuais que proporcionariam maior influência do auditório. Dentro do sistema retórico, a parte que segue essa primeira concepção é a dispositio, definida por Cícero como "a distribuição dos tópicos que foram concebidos com ordem regular". ${ }^{2}$

Essa parte da retórica ficou mais conhecida pela acepção encontrada na Institutio Oratoria, de Quintiliano, onde ele a apresenta e a desenvolve com muitos pormenores, chegando à seguinte estrutura formal do discurso: exordio, ou proêmio, parte onde se introduz o discurso e se capta a atenção do auditório; narratio, onde se apresenta o problema para o qual irá se propor uma tese; propositio, onde a tese é propriamente apresentada; confutatio, onde se argumenta em defesa da tese proposta; refutatio, parte que abriga as contra-argumentações e suas refutações; peroratio, conclusão do discurso, onde são sumarizados os principais pontos e o modo como eles foram efetivos em defender a tese principal. ${ }^{3}$ Entretanto, é interessante notar que essa é uma atualização de Quintiliano justamente porque seu pensamento não coincide exatamente com os postulados aristotélicos, como será discutido mais adiante.

A adaptação que os dados iniciais devem sofrer não é apenas no âmbito do posicionamento, mas também da própria realização da ideia enquanto material. $\mathrm{O}$ exemplo de Aristóteles permanece sendo o mais claro para o entendimento sobre o 
modo como um mesmo fato pode ser apresentado de maneiras díspares, dependendo do intento persuasivo do orador: Orestes poderia ser o assassino de sua mãe, mas também o vingador de seu pai. ${ }^{4}$ Nesse ponto, perpassa um conceito fundamental a toda a tradição retórica que é o kairos, que encontra uma problemática já em sua definição, mas que basicamente compreende o exame da situação na qual o discurso se dará para que ele se adeque a tal demanda.

Sendo assim, a reflexão sobre a ocorrência desse trabalho formal na contemporaneidade, mais especificamente dentro do discurso musical, passa basicamente por duas discussões principais. O primeiro ponto é a questão da forma enquanto estrutura organizacional tomada a priori na construção do discurso. O segundo, a adaptação de uma ideia em relação ao intento persuasivo do discurso como um todo.

\section{Aplicações da dispositio na música antiga}

Tão logo a música passou a fazer uso da retórica como um conjunto de princípios que conduziria à persuasão de outrem, ela também assumiu suas diretrizes acerca da disposição do material e seu desenvolvimento dentro do corpo discursivo. Não é demais lembrar que o principal tratado de retórica e mais constante objeto de estudo na área era a Institutio Oratoria, de Quintiliano. ${ }^{5}$ Logo, o entendimento dessa dimensão discursiva partia, para boa parte dos músicos, das proposições estruturais mais complexas de Quintiliano.

Mesmo dentro de peças cuja organização harmônica denotaria uma forma binária, a disposição das frases em seu arranjo figurativo cumpriria de maneira mais ou menos clara a estrutura retórica, desenvolvimento esse que foi gradualmente se esclarecendo. ${ }^{6}$ Essa aproximação em direção à estrutura do discurso retórico operava não só na construção de peças específicas, mas também na organização de grandes obras, como é o caso da Oferenda musical, de J. S. Bach ${ }^{7}$, onde a controversa ordem dos movimentos só foi estabelecida quando foi entendido o significado complementar que a grande estrutura tem e sua origem na retórica de Quintiliano, ainda que através dos manuais escritos pelo reformador protestante Philipp Melanchton (1497-1560).

Mesmo que essa relação possa nos parecer forçada, é necessário compreender que por mais teóricas que as discussões fossem, o foro real onde a controvérsia se estabelecia era a própria música. A segmentação do discurso dialogava assim com as segmentações do próprio falar e, ao se aproximar desse padrão, permitia que os afastamentos dele também tivessem seu valor expressivo. Ordenavam-se os eventos de modo que as sucessões fossem feitas obedecendo à constituição de coerência entre os materiais, para que quando essa ordem fosse rompida, tal ato fosse por si mesmo um evento.

Uma grande revisão feita sobre essa questão é aquela de Mark Evan Bonds em seu livro 
Wordless Rhetoric. Bonds acompanha o desenvolvimento dos tratados de composição desde o Der Vollkommene Capellmeister, escrito em 1738 por Johann Mattheson (16811764) e mostra como a compreensão da forma estava intimamente ligada ao modelo retórico em um sentido mais amplo do que a mera disposição fraseológica ou ao cumprimento de um certo tipo de estrutura harmônica. A formalização do discurso musical, ou seja, a emancipação desse aspecto como uma estrutura externa às demais, foi acontecendo gradualmente, seguindo o mesmo caminho do abandono do estudo da retórica como disciplina. Isso culminou na compreensão formal romântica que objetivava a organicidade da forma, como se essa dimensão já estivesse circunscrita dentro do material temático, não como potencialidade, mas como contingência, cabendo ao "gênio" explicitá-la, fazendo germinar a planta que a semente determina dentro de si. ${ }^{8}$

A maior contribuição de Bonds ao estudo da forma em sua ascendência retórica é a compreensão que ele apresentava da forma, ainda no classicismo, como estrutura tanto conformativa, quanto generativa. A forma conformativa é aquela que acontece a priori e, portanto, oferece à música um direcionamento estrutural a ser cumprido, cabendo ao material musical se conformar a ela. Já a forma generativa é aquela que se dá a posteriori, simultânea ao processo composicional, sendo ela mesma uma criação desse processo como um material musical moldável. Essa visão bipartida da forma possibilita a compreensão sobre a maneira pela qual a organização do discurso agregaria ao valor da persuasão, pois mais necessário do que atender àquilo que já havia sido feito em discursos concorrentes era conseguir comunicar uma ideia musical através da própria manipulação da forma. Isso justifica a existência de uma noção paradoxal de forma que há na análise hoje, onde procura-se o cumprimento de uma estrutura formal rígida, e ao mesmo tentam-se explicar as decisões que porventura não caibam nessa compartimentalização.

Desde o romantismo estabeleceu-se um modelo analítico que eliminou o âmbito generativo da forma e que permaneceu interpretado unicamente como uma fôrma, ou seja, em sua acepção conformacional. Toda a significação que a retórica atribuía a esse processo, que acabou por gerar as formas de sonata, foi diluída em uma busca por modelos universais, que culminou na grande "forma-sonata", não só então praticada, mas também atribuída ao repertório anterior. O problema é que a autonomia dada ao aspecto formal não é suficiente para interpretar nem ao menos essa música do período clássico. A razão é que a grande tese nessa música tonal do século XVIII não era a organização melódica ou harmônica, mas a própria tonalidade. A organização melódica e harmônica, na verdade, eram recursos, "argumentos" para se defender ou afirmar essa grande proposição que era obedecida e desafiada dentro do discurso e, portanto, se comportavam como material generativo.

A concepção estrutural de Quintiliano era vista menos como um arcabouço rígido e mais como ponto de reflexão para o compositor sobre o lugar de entendimento da audiência. $\mathrm{O}$ trecho inicial de uma peça conteria uma funcionalidade proêmica por mais que não 
tenha sido concebido com tal intento, pois inevitavelmente ele seria a introdução de um dado discursivo dentro da dimensão temporal. Essa lógica conduz a uma compreensão da forma como as fases do processo de adesão ${ }^{9}$, operando em função do auditório. ${ }^{10} \mathrm{Na}$ realidade, se for revisto o próprio tratado de Aristóteles é possível identificar uma discrepância fundamental quanto à concepção da dispositio em seu trabalho retórico.

Aristóteles introduz sua apresentação das partes do discurso enfatizando que deve-se tomar a distribuição dos dados em duas seções, ambas exposição e demonstração, sendo que na primeira a tese é apresentada e na segunda ela é provada. Apenas a partir dessa ênfase Aristóteles irá explanar brevemente sobre as subseções, mas sem deixar de lado que o enrijecimento do discurso em torno dessas segmentações exacerbadas seria uma "distinção ridícula". ${ }^{11}$ Isso corrobora ainda mais a compreensão da forma como um estudo da percepção temporal do discurso em sua sucessão de eventos.

\section{A forma do presente}

Para que seja possível pensar em uma leitura retórica para a música contemporânea, é necessário também pensar em uma acepção contemporânea da própria retórica. Esse é justamente o papel desempenhado pelo Tratado da argumentação: a nova retórica, escrito em 1958 pelo filósofo Chaïm Perelman e sua então assistente Lucie OlbrechtsTyteca. ${ }^{12} \mathrm{O}$ tratado objetiva atualizar o pensamento retórico à realidade filosófica em que foi escrito e, por isso, lida com muitos dos problemas que também acometiam a música. Antes que se prossiga para o estudo das concepções contemporâneas sobre a forma musical e sobre o modo como elas almejam a adesão da audiência, parece cabível apresentar uma citação do Tratado que, apesar de extensa, define claramente as diretrizes que norteiam a visão atualizada da retórica sobre a forma do discurso:

Recusamos separar, no discurso, a forma do fundo, estudar as estruturas e as figuras de estilo independentemente da meta que devem cumprir na argumentação. Iremos mais longe até. [...] O que focalizaremos no exame da forma do discurso, na medida em que a cremos discernível de sua matéria, são os meios que possibilitam a uma determinada apresentação dos dados situar o acordo num determinado nível, imprimi-lo com certa intensidade nas consciências, enfatizar alguns de seus aspectos. É pensando nas variações de forma, nas diferentes apresentações de certo conteúdo, que, aliás, não é completamente igual quando apresentado de modo diferente, que será possível descobrir a escolha de uma determinada forma. Assim como a existência de mais de uma interpretação possível nos permite não confundir o texto com os sentidos que se Ihe atribuem, assim também é pensando nos diversos meios que o orador poderia ter utilizado para dar a conhecer ao auditório a matéria de seu discurso que conseguiremos, para as necessidades da exposição, distinguir entre os problemas levantados pela apresentação dos dados e os relativos à escolha dele. ${ }^{13}$

A forma musical entrou em colapso em meados do século $\mathrm{XX}$, devido ao engessamento criado pelos formalistas, que concebiam as macroestruturas do discurso como esqueletos inalteráveis que seria necessário manter para que se desenvolvesse a continuidade nos outros parâmetros musicais. Isso permaneceu até que a própria ideia 
de uma organização pré-estabelecida do material fosse questionada e novas estratégias passassem a ser adotadas para a organização temporal dos eventos.

Um dos momentos mais emblemáticos da reação a essa situação foi a prática da chamada música aleatória. Na busca por escapar das predeterminações, as decisões generativas seriam tomadas passo a passo da maneira mais randômica possível, fazendo uso, por vezes, até de dados ou outros dispositivos que garantissem o "descontrole" formal do compositor. Entretanto, mesmo esse procedimento se esgotou e mostrou sua debilidade quando confrontado com o fato de que, embora os eventos localizados pudessem divergir de momento a momento, a grande estrutura que abrigaria as seções aleatórias deveria ser de uma maneira ou de outra disposta pelo compositor, que não seria capaz de organizar possibilidades infinitas de variabilidade, incorrendo novamente na constituição de uma estrutura formal.

A experiência aleatória foi importante para conduzir o pensamento sobre a forma musical para um próximo estágio, que agiu de maneira mais madura frente às suas limitações e possibilidades, que foi a concepção da obra artística como uma obra aberta. ${ }^{14} \mathrm{O}$ conceito tenta delimitar os espaços que permanecem livres de influência formal, de modo a explorar essas lacunas com construções que possibilitem uma maior independência para a recepção. ${ }^{15}$ O compositor italiano Luciano Berio explica do seguinte modo a preponderância da forma generativa:

Uma concepção de forma musical que tende à abertura implica no desejo - se não exatamente na possibilidade - de seguir e desenvolver caminhos formais que sejam alternativos, inesperados, não-homogêneos, e o mais importante, não lineares. Mas alternativos e inesperados com relação ao quê? Obviamente, principalmente com relação a termos estabelecidos pelo compositor na concepção concreta do trabalho. Em qualquer obra que pode ser definida como aberta, há um óbvio paradoxo. ${ }^{16}$

Esse caminho conduz à necessidade de uma proposição sobre a forma do discurso que se mostre epistemologicamente coerente frente a um pensamento artístico que identifica a própria noção de forma como insuficiente, ou seja, que questiona o duplo matéria $x$ forma. ${ }^{17}$ O filósofo francês Gilbert Simondon (1924-1989) propõe, em contraposição às teses substancialistas, que os processos físicos e coletivos são, na verdade, operados através do mecanismo da individuação, que é a atualização do pré-individuo virtual, metafísico. Dá-se lugar assim a um movimento de constante devir, impulsionado pelas forças energéticas em jogo. ${ }^{18}$ Trata-se justamente da impossibilidade de se isolar a informação da forma, de se poder compreender uma matéria amorfa ou uma forma pura. ${ }^{19}$

Dentro da realidade do discurso musical, auxilia o desdobramento da individuação, dado por Simondon, o processo alagmático, termo vindo do grego que denota mudança, em um sentido mais amplo e extremo. Esse processo abarca duas operações, que são as de modulação e de demodulação, que funcionam justamente como um agenciamento de 
forças que oferece continuidade a uma sucessão de eventos ou objetos musicais, dentro da dimensão temporal. ${ }^{20}$ Como resultado, tem-se gerado um corpus comunicativo, nos âmbitos analíticos e simbólicos, através da sucessão de continuidades e cortes do material sonoro.

A partir dessa concepção, parece ilegítima a busca por uma compreensão retórica da forma na música contemporânea, pois a arte clássica de fato propõe estruturas básicas de disposição, ainda que exposição e prova, e identifica importância para a ordem de apresentação dos materiais. Isso se dá justamente pelo fato de a retórica clássica partir do pressuposto aristotélico da hilemorfia, que entende como entidades separadas matéria e forma. Todavia, mais uma vez a revisão da Nova retórica se mostra fundamental para que essa relação possa ser discutida. Devido à centralidade dada ao auditório dentro das relações discursivas e suas negociações de significado, a forma passa a ser vista mais no seu papel de produtora de sentido do que como operadora organizacional. É por isso que o trecho supracitado (no início da seção) enfatiza tanto que essa relação é absolutamente interdependente, sendo que matéria e forma dialogam não como substâncias, mas como unidades perceptivas, compondo ambas o material discursivo que conduz à adesão: "É pensando nas variações de forma, nas diferentes apresentações de certo conteúdo, que aliás não é completamente igual quando apresentado de modo diferente". ${ }^{21}$ Assim, a forma a priori dá lugar a um mise-en-forme, uma forma que na realidade não se refere a um atributo do discurso, mas sim a um atributo da percepção em formatação, que comunica "estratégias de escuta musical e de concepção de um tempo de escuta".22

Ao se pensar a forma do discurso musical como um processo que se dá no tempo, acaba por ser necessário definir a própria noção de tempo no qual o discurso se realiza. Dentro do arcabouço clássico havia três acepções gerais de tempo: aeon, o "tempo" da eternidade; chronus, o tempo medido, quantitativo; kairos, o tempo localizado, situacional, qualitativo. Aristóteles apresenta a retórica justamente como a arte de buscar o persuasivo em cada situação, definindo o âmbito kairótico do discurso retórico. ${ }^{23}$ Cícero latiniza não só o termo como o conceito, sob o nome de decoro. Na teoria, o decoro seria um sinônimo ao kairos, todavia, essa latinização trouxe consigo uma acepção diferente, que trazia embutida em si um juízo moral sobre o belo e o certo que seriam almejados em que cada situação. O kairos era mais do que o estabelecimento de critérios morais, pois ele visava à persuasão, dentro da qual poderia inclusive haver o belo e o certo, mas que ia além, já que se preocupava fundamentalmente com as demandas discursivas localizadas.

Isso fortalece a ideia de que a forma musical rígida e pré-estabelecida não possui total sustentação na retórica, nem mesmo na clássica, pois se o discurso lidasse com tamanho grau de aprioridade, estaria se relacionando muito mais com estruturas passadas e, portanto, cronológicas. A retórica acontece no limiar entre o topológico e o teleológico (a adesão), ou seja, no presente. As tomadas de decisão no discurso são 
frutos da relação dialógica entre orador e auditório, fazendo com que a negociação dos significados, inclusive formais, não esteja nunca engendrada previamente. Kairos é o momento da atualização do virtual, o ponto de contato entre aeon e chronus, entre o temporal e o eterno. ${ }^{24} \mathrm{~A}$ ênfase que litiga Perelman em prol do auditório implica em uma ontologia, da qual tempo e espaço são partes integrantes e essenciais, sendo a forma, assim, tanto temporal quanto ecológica.

\section{Análises formais}

A partir do exposto, fica claro que não se pretende estabelecer aqui nenhuma nova tipologia das formas, muito menos propor qualquer modo de leitura unívoca da estrutura formal dos objetos de análise. ${ }^{25} \mathrm{O}$ objetivo é identificar a maneira pela qual a disposição do material contribui para a obtenção de continuidade e pregnância através do discurso. Os dois objetos de análise são composições do italiano Luciano Berio para violoncelo solo: a Sequenza XIV, concluída em 2002 em homenagem ao violoncelista Rohan de Saram e Les Mots Sont Allés..., encomendada em 1979 pela fundação Paul Sacher por ocasião do aniversário de 70 anos de seu mecenas, razão pela qual seu material inicial é a "pseudo"-série eSACHERe (Mib, Lá, Do, Si, Mi natural e Ré). Prosseguindo, o próprio Luciano Berio parece corroborar a presente acepção de forma:

A perspectiva formal, estrutural e generativa da música de hoje, isto é, aquela pela qual tenho me interessado, são um convite à percepção dos extremos, o próximo e o distante, o banal e o complexo [...] em que a forma não é algo que "funciona", mas é agente e material de sua própria criação. ${ }^{26}$

Berio fornece assim mais um subsídio para que um critério formal já imanente em sua música fique ainda mais evidente, que é o trabalho com os contrastes, as dualidades. Assim como foi visto que a forma perceptiva estabelece continuidade através das modulações e demodulações, Berio em seu trabalho composicional possibilita a percepção formal ${ }^{27}$ quando decide interromper um determinado fluxo discursivo e adentrar outro topos aparentemente oposto, mas que mantém a continuidade através de outros parâmetros musicais. No caso da Sequenza XIV, o corte textural que acontece entre as seções polifônicas e as seções monódicas exige uma adaptação muito rápida da escuta, já que lidam com elementos também opostos, que são a maior quantidade de objetos sonoros na monodia, unidos através de síntese aditiva.

Desse modo, é possível constatar serem aspectos mantenedores da continuidade a polifonia gestual composta, sendo a forma também um material discursivo, fruto do processo, comunicado macroestruturalmente em simultâneo aos eventos localizados. É por isso que ele afirma ser um pressuposto de sua escrita uma contingência perceptiva e mnemônica, que "permite ao auditório escolher e eleger seus elementos formais", outorgando-lhe uma "parte ativa da realização da obra". ${ }^{28}$ É nesse sentido que a obra é aberta na mesma medida que um debate é aberto, servindo a retórica como uma arte de se encontrar o persuasivo em cada caso, em cada momento presente. 
A proposta de divisão formal aqui apresentada pode auxiliar, então, a compreensão dos conjuntos de significados mais próprios a cada seção, auxiliando na interpretação do discurso, dada a transformação material que implica a percepção. Adotando o critério textural, parecem evidentes as seguintes seções:

\begin{tabular}{|l|l|l|l|}
\hline SEÇÃO & LOCALIZAÇÃO & ATRIBUTO & TÉCNICA \\
\hline A & p. 1 & Textura monódica & Percussão \\
\hline B & p. $2-4$ & Textura polifônica & Arco \\
\hline A & p. 5 & Textura monódica & Percussão \\
\hline "Peroração" & p. 6 & Ambas & Ambos \\
\hline
\end{tabular}

Tabela 1: Esquema formal da Sequenza XIV

A primeira seção, $A$, tem início com uma pequena estrutura que apresenta o material técnico que é a síntese aditiva percussiva e a sonoridade paradigmática do trítono já fazendo uso da scordatura. Essas duas entidades são constituídas por gestos simples, mas que tem a função de preparar e construir a escuta demandada dali em diante como uma espécie de exordio para a acepção presente de forma. A seção segue, desenvolvendo gesto percussivo até alcançar a seqüência rítmica de 12 tempos com suas permutações.

Após o encerramento dessa seção, há uma pequena transição executada com pizzicati de mão esquerda, que possibilita que o violoncelista segure seu arco para a seção que prossegue, chamada aqui de B. A seção tem inicio com um gesto que já contém sobreposições de camadas, seguido por uma outra categoria gestual, dando inicio à polifonia de gestos característicos das sequenze. Esse desenvolvimento acontece durante as três páginas seguintes, onde, após a apresentação de cada novo gesto, acontecem os processos diálogicos entre esse gesto e os demais, sem que, contudo, se perca a clareza textural polifônica.

Na quinta página, uma nova seção percussiva tem início, tendo em comum com a primeira apenas o aspecto textural $e$, durante um pequeno trecho, o uso da seqüência rítmica de doze tempos, chamada aqui de Seção A, por trazer de volta a primeira escuta, ainda que com materiais distintos.

Por fim, tem-se na última página uma seção final, grosseiramente denominada aqui de peroração, pois traz à escuta uma recordação de todos os materiais apresentados na peça, muitas vezes aliterados. Essa sumarização procura encerrar o discurso repetindo os mesmo gestos, que, todavia, já não são mais os mesmos graças ao seu papel material que se construiu junto com o discurso. 

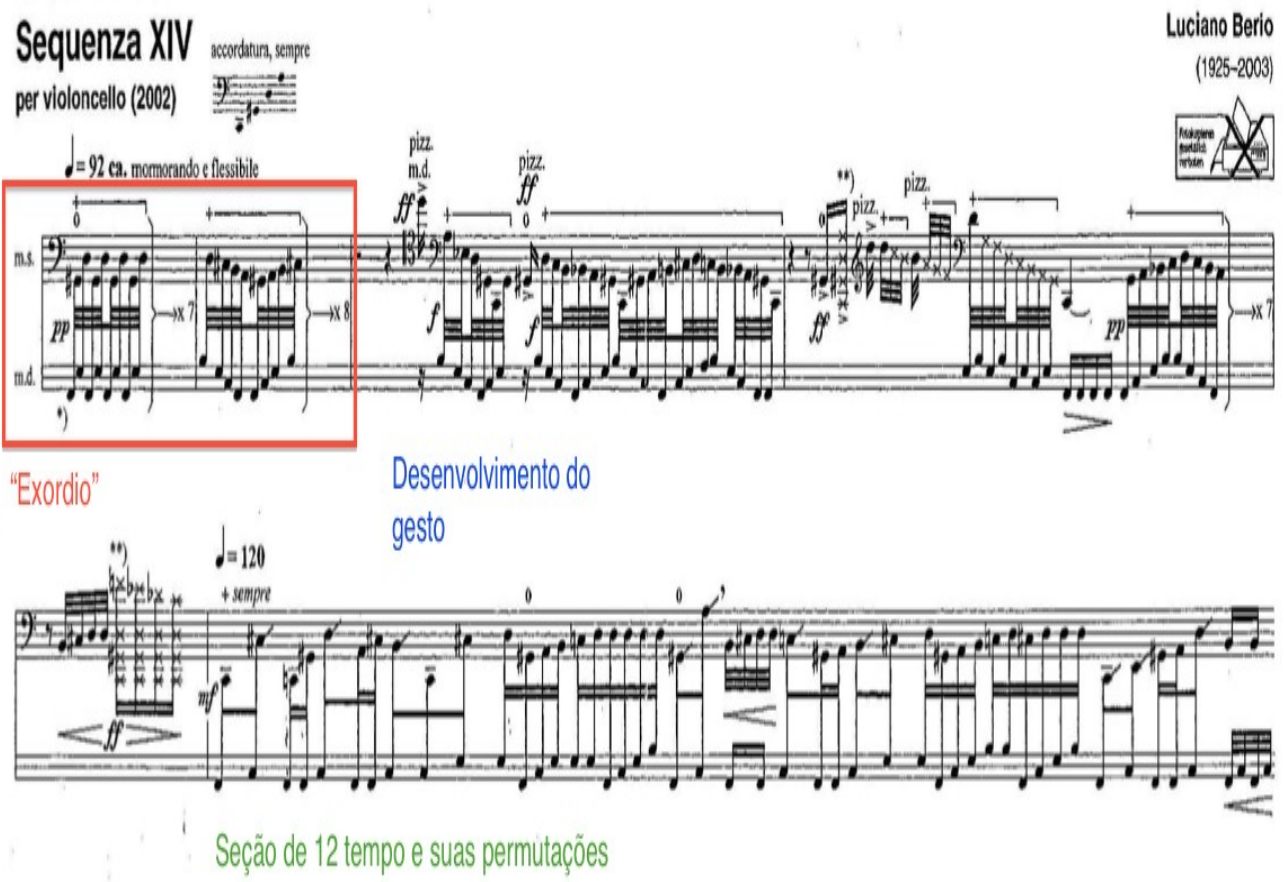

Fig. 1: Seção A, principais eventos

Depois que foi definido o presente conceito de forma, parece ser muito simples e evidente a forma emanada pela Sequenza, sendo seus significados muitos patentes. Todavia essa peça apresenta uma característica processual que em muito interessa a essa reflexão. Apesar de a escuta identificar uma forma através da sucessão temporal de eventos, essa forma generativa se dá na percepção e não necessariamente na composição. Diz-se isso pois, em sua estreia em abril de 2002 por Rohan de Saram, toda a seção $A$, a primeira página, na realidade não existia. A negociação dos significados tem assim uma total reconfiguração, já que o processo que se revela na forma passa a ter uma significação totalmente distinta.

Em sua primeira versão, a Sequenza tinha início com este trecho:

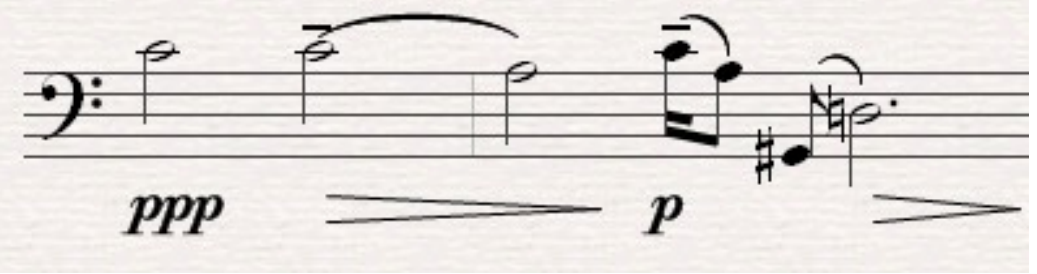

Fig. 2: Gesto inicial da primeira versão da Sequenza (Fonte: Coleção Berio/Paul Sacher Stiftung)

Embora seja possível se depreender que a versão final, concluída no mês de novembro do mesmo ano, correspondia mais aos intentos discursivos do compositor, não há como 
eliminar o fato de que a primeira estréia foi, sim, feita e a peça tinha sua forma, sua sustentação para ser levada ao palco diante do público. A grande diferença é que a antiga disposição temporal atribuía outros significados aos mesmos gestos, pois haveria uma forma mais similar a um $A-B$ - $A B$, com uma clara síntese das duas texturas apresentadas previamente na seção final.

Comprova, finalmente, a construção de significado feita por Berio o fato de que apenas na última versão, poucos momentos antes da publicação final, o gesto de quintina da página final foi enxertado nela toda, completando-a com o único gesto que não constava nessa sumarização. Aliás, mesmo a atual disposição de páginas, que divide tão claramente as seções, só atingiu esse formato na versão final. 

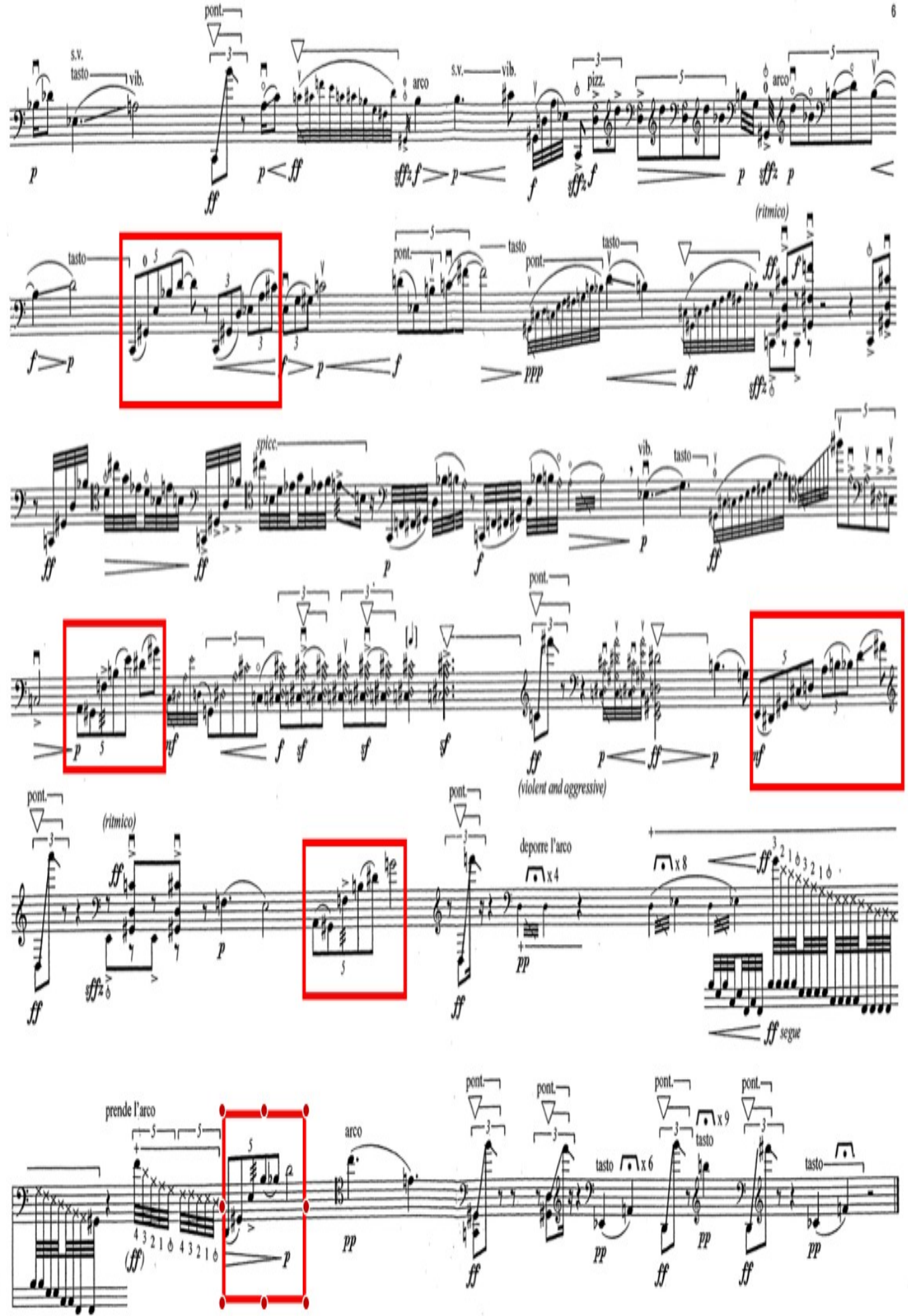

Luciano Berio Sequena XV per vidoncello (2002) ocopyight 2002by Univeral Edition AG, Wen

Universa Edotion UE 32014

Fig. 3: Nenhuma das figuras em destaque nessa última página existiam até a edição final da peça (Fonte: Coleção Berio/Paul Sacher Stiftung) 
Assim, Para Berio, a forma generativa é a única acepção da forma capaz de gerar significado dentro da realidade musical contemporânea:

Alguns compositores só estão interessados na música como forma. Eu estou muito mais interessado no aspecto formacional, na música como um processo. A fim de ir a fundo no processo, a formação de uma forma, necessita-se dessas diferentes dimensões temporais. Às vezes experimenta-se a iluminação repentina de algo que te faz pular. Então gradualmente se descobre qual realmente é sua busca. ${ }^{29}$

A liberdade formal possibilitada por seu processo composicional the dá, de fato, muito maiores possibilidades de trabalho com a forma perceptiva. $O$ auditório passa a estar em uma instabilidade tão grande quanto o próprio discurso. Passo a passo o material toma forma, e a forma se torna material, fazendo com que a ênfase na entidade receptiva seja definitivamente a melhor forma de se negociar significados para um discurso.

Essa questão está presente na Sequenza, mas acontece de uma maneira muito mais explícita em Les Mots Sont Allés.... Em seu processo composicional, a partir da série dada, Berio gerou primeiramente todas as alturas utilizadas na peça, através de um enorme contraponto da série e de um estudo de transposições, como esse:

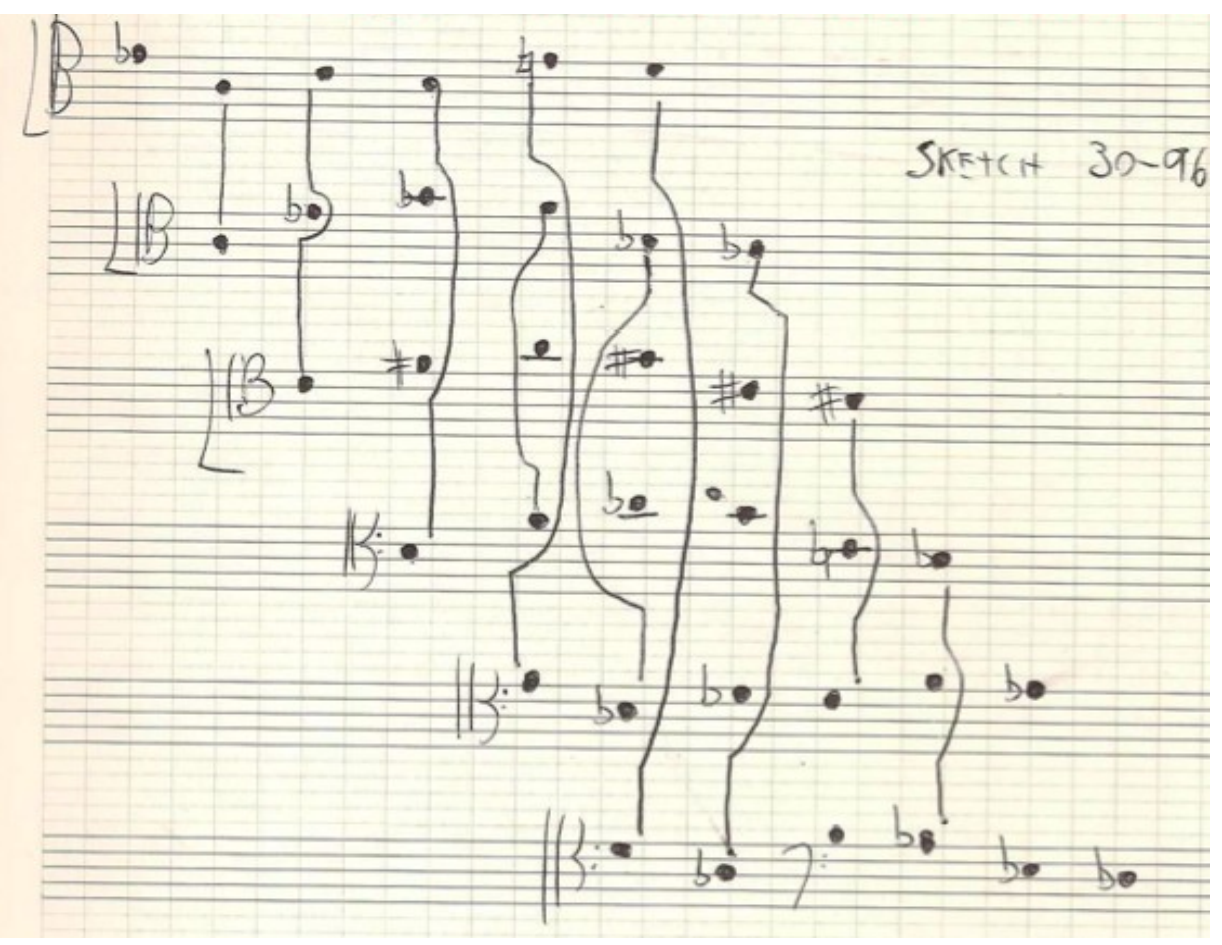

Fig. 4: Início do procedimento composicional com transposições da série. (Fonte: Paul Sacher Stiftung - cópia do autor) 
Após estabelecer todo o parâmetro melódico da peça, Berio construiu uma primeira versão onde mais da metade das figuras rítmicas da versão final estão alteradas. Sendo que a clareza da forma A-B-A' dessa versão final é definida justamente pelo parâmetro rítmico, fica evidente que a forma foi uma construção a posteriori, independente, dentro de sua definição:

Vamos imaginar uma célula de alturas, por exemplo, ou uma sequência de alturas, que gera melodias, figuras, frases e processos harmônicos. Uma configuração rítmica molda essas melodias e gera padrões, glissandos de tempo, e distribuições descontínuas, ou mesmo estáticas dessas mesmas melodias e figuras. Camadas dinâmicas, técnicas e cores instrumentais, podem anular ou aperfeiçoar os caracteres individuais de cada processo, a natureza de sua evolução e o grau de sua independência. Às vezes essa independência pode se tornar indiferença e os parâmetros musicais podem seguir sua própria vida. ${ }^{30}$

\section{Considerações finais}

A partir dessa revisão, fica claro que a música contemporânea inevitavelmente preserva uma ideia de forma, mas que necessita, para ser compreendida, que não se separem as entidades produtoras e receptoras do discurso. Se essa premissa fica clara, o exame das propriedades formais pode revelar preciosas informações sobre os significados da obra musical e suas intenções persuasivas. Para completar essa ideia, Berio faz um alerta muito interessante:

Quanto mais a linguagem musical de hoje tende a se constituir e a se formar em referência a um sistema lingüístico, mais ela renuncia a sua significação; e, o que é mais importante, quanto mais as relações das estruturas propostas são predeterminadas, mais frágil é a consciência critica do público face a essas estruturas musicais. ${ }^{31}$

A retórica musical não é um operador meramente simbólico e, se coerente com seu arcabouço original, pertence a uma arte que impregna todas as formas de discurso, em todas as linguagens. Sendo assim, a dispositio não se coloca como um molde, mas como um estudo dos efeitos persuasivos da disposição e do posicionamento do material na dimensão temporal, no kairos no qual o discurso é colocado como mediação entre orador e auditório.

A análise dos objetos aqui interpretados evidencia que a disparidade de materiais característica da música contemporânea emana uma diversidade formal, mas que mesmo assim guarda certas similaridades quanto às dualidades, os constrastes, entre as continuidades e cortes. Por fim, a acepção generativa da forma nos leva a repensar também a relação da forma com a música antiga, que já fazia uso dessa ideia, mas que tem sido reinterpretada com pressupostos analíticos românticos. Talvez hoje seja o tempo do kairos. 


\section{* Silvio Ferraz é professor associado do Departamento de Música da USP. William Teixeira da Silva é doutorando em música pela USP.}

1 BARTEL, D. Musica poetica: Musical Rhetorical Figures in German Baroque Music. Lincoln: University of Nebraska, 1997, p. 74.

${ }^{2}$ CíCERO, M. T. The Orations of Marcus Tullius Cicero. Tradução de C.D. Yonge. London: G. Bell and Sons, 1913, p. 248.

${ }^{3}$ QUINTILIANO. Institutio Oratoria. Tradução de Jeronymo Soares Barboza. Coimbra: Editora da Universidade de Coimbra, 1836, p. 72

${ }^{4}$ ARISTÓTELES. Retórica. Lisboa: Imprensa Nacional, 2005, p. 249

${ }^{5}$ BARTEL, D. Op. cit., p. 69.

${ }^{6}$ Ibidem, p. 81.

${ }^{7}$ KIRKENDALE, U. "The Source for Bach's 'Musical Offering': The 'Institutio oratoria' of Quintilian". In: Journal of the American Musicological Society, v. 33, n. 1 (Spring, 1980), pp. 88-141.

${ }^{8}$ BONDS, M. E. Wordless Rhetoric: Musical Form and the Metaphor of Oration. Cambridge: Harvard University, 1991, p. 142.

${ }^{9}$ Para maior aprofundamento ver: SILVA, W. T.; FERRAZ, S. "A adesão ao discurso musical contemporâneo: uma abordagem retórica”. In: Trivium: estudos interdisciplinares. Ano VIII, Edição I (Junho de 2015).

10 lbidem, p. 60

${ }^{11}$ ARISTÓTELES. Op. cit., p. 278.

12 PERELMAN, C.; OLBRECHTS-TYTECA, L. Tratado da argumentação: a nova retórica. Tradução Maria Ermantina Galvão G. Pereira. São Paulo: Martins Fontes, 1996.

${ }^{13}$ Ibidem, p. 162.

${ }^{14}$ Expressão cunhada pelo escritor, e grande amigo do compositor Luciano Berio, Umberto Eco, no livro homônimo Obra Aberta. A influência da retórica na teoria narrativa do autor é mais explorada em ECO, U. O super-homem de massa: retórica e ideologia no romance popular. Tradução de Pérola de Carvalho. São Paulo: Editora Perspectiva, 1991.

${ }^{15}$ BONAFÉ, V. M. Estratégias composicionais de Luciano Berio a partir de uma análise da Sonata per Pianoforte. Dissertação de mestrado: USP, 2011, p. 22.

${ }^{16}$ BERIO, L. Remembering the Future. Cambridge: Harvard University: 2006, p. 80.

17 DELEUZE, G.; GUATTARI, F. Mil platôs. v. 3. Tradução de Suely Rolnik. São Paulo: Editora 34, 1997, p. 90.

${ }^{18}$ DAMASCENO, V. "Notas sobre a individuação intensiva em Simondon e Deleuze". In: O que nos faz pensar, n. 21 (2007), p. 174.

19 Ibidem, p. 175 e SIMONDON, G. Cours sur la perception. Chatou: Les Éditions de la Transparence, 2006, p. 78.

${ }^{20}$ FERRAZ, S. "Kairos-point d'interruption”. In: Simondon, Deleuze, Guattari et l'écologie du son. Université Paris 8 (outubro de 2014), p. 7

${ }^{21}$ PERELMAN, C.; OLBRECHTS-TYTECA, L. Op. cit., , p. 162.

${ }^{22}$ FERRAZ, S. "Considérations sur forme musicale et forme d'écoute". In: International Semiotic Studies Congress, Aix en Provence, 1998, p. 1.

${ }^{23}$ KINNEAVY, J. L. "Kairos in Classical and Modern Rhetorical Theory". In: SIPIORA, P.; BAUMLIN, 
J. (orgs). Rhetoric and Kairos: Essays in History, Theory, and Praxis. Albany: State University of New York, 2003, p. 66.

${ }^{24}$ LESTON, R. "Unhinged: Kairos and the Invention of the Untimely". In: Atlantic Journal of Communication, 2013, p. 35.

${ }^{25}$ FERRAZ, S. "Considérations sur forme musicale et forme d'écoute”. Op. cit., p. 7.

${ }^{26}$ BERIO,. "Delle forme”. In: BERIO, L. Scritti sulla musica. Torino: Einaudi, 2013, p. 85.

${ }^{27}$ BERIO, L. Contrechamps. v. 10. Paris: L’Age D’Homme, 1983, p. 19.

${ }^{28}$ Ibidem, p. 19.

${ }^{29}$ BERIO, L.; MULLER, T. "'Music is not a solitary act': conversation with Luciano Berio". In: Tempo, New Series, n. 199 (Jan, 1997), pp. 16-20, aqui p. 19.

${ }^{30}$ BERIO, L. Remembering the Future. Op. cit., p. 13.

${ }^{31}$ BERIO, L. Contrechamps. Op. cit., p. 37. 